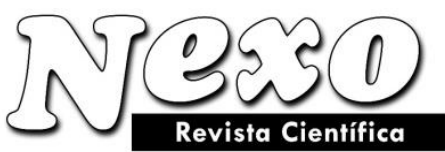

Vol. 33, No. 01, pp. 200-212/Junio 2020

\title{
PROVIDING OPTIMAL DYNAMIC MODEL OF TRAFFIC LIGHTS IN SUPER SATURATED CONDITIONS WITH EMPHASIS ON ATM
}

\section{PROPORCIONANDO UN MODELO DINÁMICO ÓPTIMO DE LUCES DE TRÁFICO EN CONDICIONES SÚPER SATURADAS CON ÉNFASIS EN}

\author{
ATM \\ Hooman Rahimi ${ }^{1}$, Hasan Zoghi*2 ${ }^{2}$, Saeed Monajem ${ }^{3}$ \\ ${ }^{1}$ School of Civil Engineering, Central Tehran Branch, Islamic Azad University, Tehran, Iran.Email: \\ Hoomanrahimit@yahoo.com. ORCID ID: https://orcid.org/0000-0003-4329-7732 \\ ${ }^{2}$ Department of Civil Engineering College of Technical and Engineering, karaj Branch, Islamic Azad \\ University, Alborz, Iran. Corresponding autor. Email: Hasanzoghi1344@ yahoo.com . ORCID ID: \\ https://orcid.org/0000-0003-1115-2694
}

${ }^{3}$ Department of Civil Engineering College of Technical and Engineering, Central Tehran Branch, Islamic Azad University Tehran, Iran. Email: S.monajem @yahoo.com. ORCID ID:https://orcid.org/0000-00030946-2925

(recibido/received: 07-enero-2020; aceptado/accepted: 15-mayo-2020)

\begin{abstract}
Dynamic signal control strategies are effective in relieving congestions during nontypical days, such as those with high demands, incidents with different attributes, and adverse weather conditions. This research recognizes the need to model the impacts of dynamic signal controls for different days representing, different demand and incident levels. Methods are identified to calibrate the utilized tools for the patterns during different days based on demands and incident conditions utilizing combinations of real-world data with different levels of details. A significant challenge addressed in this study is to ensure that the mesoscopic simulation-based dynamic traffic assignment (DTA) models produces turning movement volumes at signalized intersections with sufficient accuracy for the purpose of the analysis. A new model is developed to estimate the drop in capacity at the incident location by considering the downstream signal control queue spillback effects. A second model is developed to estimate the reduction in the upstream intersection capacity due to the drop in capacity at These regression models are combined with the DTA model to estimate the volume at the incident location and alternative routes. The volumes with different demands and incident levels, resulting from DTA modeling are imported to a microscopic simulation model for more detailed analysis of dynamic signal control. The microscopic model shows that the implementation of special signal plans during incidents and different demand levels can improve mobility the midblock incident location as estimated by the first model measures.
\end{abstract}

Keywords: Dynamic model; Active Traffic Management (ATM); Transportation; Travel. 
Silva, F.M., Marenco, G.A. y Zelaya, C.E.

\section{RESUMEN}

Las estrategias de control dinámico de la señal son efectivas para aliviar las congestiones durante los días no típicos, como aquellos con altas demandas, incidentes con diferentes atributos y condiciones climáticas adversas. Esta investigación reconoce la necesidad de modelar los impactos de los controles de señal dinámica para diferentes días que representan diferentes niveles de demanda e incidentes. Los métodos se identifican para calibrar las herramientas utilizadas para los patrones durante diferentes días en función de las demandas y las condiciones del incidente utilizando combinaciones de datos del mundo real con diferentes niveles de detalles. Un desafío importante abordado en este estudio es garantizar que los modelos de asignación dinámica de tráfico (DTA) basados en simulación mesoscópica produzcan volúmenes de movimiento de giro en intersecciones señalizadas con suficiente precisión para el propósito del análisis. Se desarrolla un nuevo modelo para estimar la caída de la capacidad en la ubicación del incidente considerando los efectos de derrame de la cola de control de señal aguas abajo. Se desarrolla un segundo modelo para estimar la reducción en la capacidad de intersección aguas arriba debido a la caída en la capacidad en Estos modelos de regresión se combinan con el modelo DTA para estimar el volumen en la ubicación del incidente y las rutas alternativas. Los volúmenes con diferentes demandas y niveles de incidentes, resultantes del modelado DTA se importan a un modelo de simulación microscópica para un análisis más detallado del control dinámico de la señal. El modelo microscópico muestra que la implementación de planes de señales especiales durante los incidentes y los diferentes niveles de demanda pueden mejorar la movilidad en la ubicación del incidente en el bloque medio según lo estimado por las primeras medidas del modelo.

Palabras clave: Modelo dinámico; Gestión activa del tráfico (ATM); Transporte; Viajes.

\section{INTRODUCCIÓN}

Active Traffic Management (ATM) is an important component of Transportation System Management and Operations (TSM\&O) and Active Traffic Demand Management (ATDM), providing significant benefits in terms of travel time, travel time reliability, emission, fuel consumption, safety, and other performance measures of the transportation systems. There is an urgent need for decision support systems to support ATM strategies (Avetisyan, Miller-Hooks, Melanta, \& Qi, 2014). This is particularly true for ATM strategies on urban streets, as agencies start moving their focus to these streets. Agencies have encountered other challenges, including their need to identify the urban street corridors that benefit the most from ATM implementation, what strategies are the most advantageous, in addition to the magnitude of the benefits, costs and their implementation barriers under different conditions and unreliability sources such as incidents, high demands and severe weathers conditions (Shams, Jin, Fitzgerald, Asgari, \& Hossan, 2017). Agencies are also interested in assessing the benefits and costs in investing in ATM strategies versus investing in capacity improvements such as adding lanes or interchange modifications. Therefore, ATM strategies are becoming crucial components of transportation system planning and operations. Various levels of modeling tools including sketch planning, macroscopic, mesoscopic, microscopic simulations tools combined with static or dynamic traffic assignment have been applied by transportation agencies to model advanced traffic management strategies (Bhide, 2005). Multi-resolution modeling (MRM) is an integrated approach that combines different modeling levels that can be used as an effective method for the assessment and support of ATM strategies and to support mitigating transportation system congestion problems. However, there is a need for methods and tools to allow agencies to use MRM in general and to use MRM in evaluating ATM in particular. This dissertation develops and uses methods for the use of MRM to support agency decisions related to ATM strategies deployment on urban streets (Hadi, Sinha, \& Wang, 2007; Hadi et al., 2016). 


\section{METHODOLOGY}

The first step was the data acquisition. Data from multiple sources and agencies was collected and processed to develop and calibrate models. Next, acombination of tools were selected for the modeling and analysis of this research. After the tool selection, the next step was network preparation for modeling. The network geometry was imported, updated, and cleaned to better represent the existing real-world network (Hong, Yue-sheng, \& Bin, 2013). Different traffic patterns were identified for modeling to represent different demands and congestion levels. Then, the traffic network and demand parameters (supply and demand) of the simulation-based DTA models were calibrated for different demand levels utilizingreal-world measures such as traffic flow, on each link and on each turning movement (Jin, Hossan, Asgari, \& Shams, 2018). The trip matrices were estimated for 15 minutes' time intervals for input to the DTA models. An Origin Destination Matrix Estimation (ODME) process was implemented through three levels of calibration. In the first level (the network level), the overall network was calibrated. Since the arterial streets are the focus of this study, in the second level, a more detailed calibration of the demands on arterial street segments was conducted. In the third level, the demands of the intersections' turning movements were calibrated through a focus calibration on these movements. The next steps in the model preparation for modeling was to prepare the microscopic simulation model network. The calibrated model was imported from the simulation-based DTA tool to the microscopic tool. The combination of the two tools allowed the assessment of the traffic and incident responsive signal control.

\section{RESEARCH BACKGROUND}

ATDM strategies dynamically control and manage traffic demand, travel demand, and traffic flow of transportation facilities (Aghdashi, Khazraeian, Trask, Hadi, \& Rouphail, 2017; S Khazraeian, Hadi, \& Xiao, 2017; Samaneh Khazraeian, Xiao, Hadi, \& Aghdashi, 2015). The Federal Highway Administration's (FHWA) ATDM programs was introduced to support active, integrated and performance-based solutions to enhance safety, maximize system productivity, and improve individual mobility in multi-modal surface transportation systems. Examples of ATDM strategies are shown in Table 1 (Hadi, et al., 2016).

Table 1. Examples of ATDM Strategies

\begin{tabular}{|l|l|l|}
\hline $\begin{array}{l}\text { Active Traffic } \\
\text { Management (ATM) }\end{array}$ & $\begin{array}{l}\text { Active Demand } \\
\text { Management (ADM) }\end{array}$ & $\begin{array}{l}\text { Active Parking } \\
\text { Management (APM) }\end{array}$ \\
\hline Adaptive Ramp Metering & Dynamic Fare reduction & $\begin{array}{l}\text { Dynamic Overflow } \\
\text { Transit Parking }\end{array}$ \\
\hline $\begin{array}{l}\text { Adaptive Traffic Signal } \\
\text { Control }\end{array}$ & $\begin{array}{l}\text { Dynamic HOV/Managed } \\
\text { Lanes }\end{array}$ & $\begin{array}{l}\text { Dynamic Parking } \\
\text { Reservation }\end{array}$ \\
\hline Dynamic Junction Control & Dynamic Pricing & Dynamic Wayfinding \\
\hline $\begin{array}{l}\text { Dynamic Lane Reversal or } \\
\text { Contraflow Lane Reversal }\end{array}$ & Dynamic Ridesharing & Dynamic Priced Parking \\
\hline Dynamic Lane Use Control & Dynamic Routing & \\
\hline Dynamic Merger Control & $\begin{array}{l}\text { Dynamic Transit Capacity } \\
\text { Assignment }\end{array}$ & \\
\hline Dynamic Shoulder Lanes & On-Demand Transit & \\
\hline Dynamic Speed Limits & $\begin{array}{l}\text { Predictive Traveler } \\
\text { Information }\end{array}$ & \\
\hline Queue Warning & $\begin{array}{l}\text { Transfer Connection } \\
\text { Protection }\end{array}$ & \\
\hline Transit Signal Priority & & \\
\hline
\end{tabular}

Nexo Revista Científica / Vol. 33, No. 01, pp. 200-212 / Junio 2020 


\section{RESEARCH FINDINGS}

Incident management is a vital part of ATM strategies. Estimating the impact of incidents and incident management allows traffic management agencies to determine the need for various incident management strategies and technologies to justify the decision to invest in their programs. This research describes a new approach to estimate the capacity impacts due to arterial incidents that result from the interaction between the drop in capacity below demands at midblock urban street segment locations and upstream and downstream signalized intersection operations. This research also describes the development and application of a new model that can estimate the impacts of incidents and incident management strategies on urban street facilities. The developed method was successfully used to estimate the impact of modifying signal timing plans during incidents with consideration of the estimating drop in capacity.

\subsection{Estimating the capacity impacts of urban street incidents}

Thus, the upstream movement greens can be divided into two parts. The first part, referred to as the "unconstrained green" in this study, is the green time portion that vehicles from the upstream links can leave at the throughput of upstream links due to the availability of queuing storage at the downstream link. In the second part, referred to as the "constrained green," the movements from the upstream links are controlled by the capacity at the incident location due to the spillback of the queues from the downstream incident. The result of having this constrained green is a reduction in the capacity of the upstream intersection feeding links, which causes an increase in the upstream movement delays.

On the other hand, incident link capacity can be affected by the downstream intersection queue if it spills back to the upstream incident location. In addition, a reduction in link capacity due to incidents can prevent vehicles from arriving at downstream signalized intersections, reducing the utilization of downstream green movement and thus the capacity. Consequently, this decreases downstream intersection queue discharges.

\subsection{Calibration of microscopic simulation for no-incident conditions}

Two of the urban driver car-following models in VISSIM (Wiedemann 74 driver behavior model) were fine-tuned in this study in order to obtain the target saturation flow rate: 1) the additive part of desired safety distance (bx_add); and 2) the multiplicative part of the desired safety distance (bx_mult) (Al-Nuaimi, Ayers, \& Somasundaraswaran, 2013; Kim, Kim, \& Rilett, 2005). These parameters determine the desired safety distance, which has a direct impact on saturation flow rate (26). The most appropriate combination of the two parameters was found to be 2.4 feet for the additive part of the desired safety distance and 3.4 for the multiplicative part of the desired safety distance. The resulting saturation flow rate for the simulated thru movement was 1,854 passenger cars per hour per lane based on the average of ten simulation runs with different random seeds.

\subsection{Estimating capacity drop due to incidents at the movement stop lines}

Once the network was calibrated for no-incident conditions, it was necessary to model the incident conditions. In order to model incident impacts using simulation, it was necessary to emulate the estimated drop in capacity at the incident location in the simulation model. The capacity drop at the incident location was estimated based on the equations developed in the SHRP2 Program L08 project referenced earlier (Zegeer et al., 2014). The equations used in the estimation is as follows:

$$
\text { bic, int (i), } n, m=0.58 \text { Ifi, int (i), } n \text { 0.42I pdo, int (i), } n+0.17 \text { Iother, int (i), } n
$$

fic, $n t(i), n, m, a p, d=$ saturation flow adjustment factor for incident influence on movement $\mathrm{m}(\mathrm{m}=\mathrm{L}$ : left, T: through, R: right) at intersection i

Nexo Revista Científica / Vol. 33, No. 01, pp. 200-212 / Junio 2020 


\section{Hooman Rahimi et al.}

$N n, n t(i), n, m=$ number of serving movement lanes (m) on leg associated with phase (n) at intersection $\mathrm{i}$ Nic,int(i),n,m,ap,d = number of serving movement lanes $(m)$ blocked by the incident on leg associated with phase (n) at intersection i

bic, int(i), $n=$ calibration coefficient on leg associated with phase (n) at intersection $\mathrm{i}$

Ifi, int (i), $n=$ indicator variables for fatal-or-injury on leg associated with phase (n) at intersection $i$

I pdo, int (i), $\mathrm{n}=$ indicator variables for property damage only (PDO) on leg associated with phase (n) at intersection $\mathrm{i}$

Iother, $n t(i), n=$ indicator variables for non-crash incident on leg associated with phase (n) at intersection

\subsection{Modeling incidents in microscopic simulation}

This section describes the calibration of microscopic simulation models for incident conditions in VISSIM. VISSIM does not allow the user to specify incidents in the model. This section describes the calibration of microscopic simulation models for incident conditions in VISSIM. VISSIM does not allow the user to specify incidents in the model.

Previous studies modeled incidents by setting up a red signal at the incident lane using vehicle(s) with zero speed at the time and location of the incident (Avetisyan, et al., 2014) or using buses with dwelling times equal to the lane blockage durations (Hadi, et al., 2007). In this study, the incidents were simulated in VISSIM using bus stops with dwell times equal to incident duration on the blocked lanes. This was combined with a reduced speed area on the adjacent lanes to emulate drivers slowing down to observe the incident (Hadi, et al., 2007; Zhou \& Taylor, 2014). The length of "reduce speed area" in the vicinity lanes of the incident was modified by trial and error to achieve the abovementioned expected drop in capacity due to the uninterrupted incident. "Uninterrupted incident" refers to the incident that is not affected by downstream signal queue spillbacks.

\subsection{Assessing the impacts of downstream signal on upstream incident capacity}

Based on the simulation results for one lane blockage, the upstream incident capacity was not found to be affected by the downstream intersection when the incidents occur at 400.m and 433.m. from the downstream signal and when the $\mathrm{g} / \mathrm{C}$ ratio at the downstream signal equals 0.67 and 0.55 , respectively. These values were selected for use in the analysis based on typical $\mathrm{g} / \mathrm{C}$ ratios for the main street in the analysis area. Reducing the $\mathrm{g} / \mathrm{C}$ ratio to a level that constrains the departing volumes from the upstream link is expected to reduce the traffic volume arriving at the downstream incident location, and this may reduce the portion of unconstrained green. For the two-lane blockage incident, the capacity at the incident location was not affected significantly by the downstream intersection when the incident occurs at $75 \mathrm{~m}$. or more from the downstream signal. This distance is the same for both $\mathrm{g} / \mathrm{C}$ ratios $(0.55$ and 0.67$)$.

The data presented was used to develop regression models to estimate the incident capacity (IC) based on the investigated influencing factors. The developed regression models are presented in Table 2. The developed regression models show that there is a significant relationship between the incident capacity and the three independent variables, mentioned earlier, as indicated by the Coefficient of Determination (RSquared) values and the t-test of the significance of the independent variable coefficients. If the $\mathrm{g} / \mathrm{C}$ ratio for an assessed condition is between the two $\mathrm{g} / \mathrm{C}$ ratios assessed in this study, as displayed in Table2, interpolation can be used to estimate the capacity.

Nexo Revista Científica / Vol. 33, No. 01, pp. 200-212 / Junio 2020 
Table 2. Upstream interrupted incident capacity regression models

\begin{tabular}{|c|c|c|c|}
\hline $\begin{array}{c}\text { Number of } \\
\text { Lane Blockage }\end{array}$ & $\begin{array}{c}\text { Downstream } \\
\text { Signal g/C }\end{array}$ & Upstream Incident Capacity & R2 \\
\hline One Lane & 0.67 & IC $=0.624 x+532$ & 09216 \\
Blockage & 0.55 & IC $=0.5922 x+646.23$ & 09023 \\
\hline Two Lane & 0.67 & IC $=6 \mathrm{E}-07 \times 3-0.0015 \times 2+1.1292 x+192.34$ & 08915 \\
Blockage & 0.55 & IC $=4 \mathrm{E}-07 \times 3-0.0011 \times 2+0.839 x+212.18$ & 09082 \\
\hline
\end{tabular}

\subsection{Assessing the impacts of incidents on upstream intersection maximum throughputs}

A second model was developed in this study to estimate upstream intersection maximum throughput as impacted by the drop in capacity due to a downstream signal. The maximum throughput was assessed for incidents with different distances from the upstream intersection, different volume-to-capacity incident link ratios $(\mathrm{v} / \mathrm{Ic})$, and different incident durations. This was conducted by introducing incidents at different locations with different capacity drops and different incident durations in a VISSIM model. The incident durations were 15 minutes, 35 minutes, and 45 minutes. It should be noted that 35 minutes is the median incident duration at the study location.

Figures 1 to 3 show the variation in the upstream intersection maximum throughput with the incident location, incident duration and the v/Ic ratio at the incident location. In these figures, the incident location references the distance from the upstream signal stop line. It should be also noted that the saturation flow of the upstream signal without incident is $5,562 \mathrm{veh} / \mathrm{hr}$. Thus, incidents with downstream locations and v/Ic ratios that produce this upstream intersection saturation flow in the simulation are recognized as incidents that do not impact upstream signal operations. For example, the investigated 35- minute incident did not affect the upstream intersection throughput when it is located more than $470 \mathrm{~m}$., $730 \mathrm{~m}$., and $920 \mathrm{~m}$. from the upstream signalized intersection with the v/Ic ratio at the incident location of $1.13,1.3$ and 1.5, respectively.

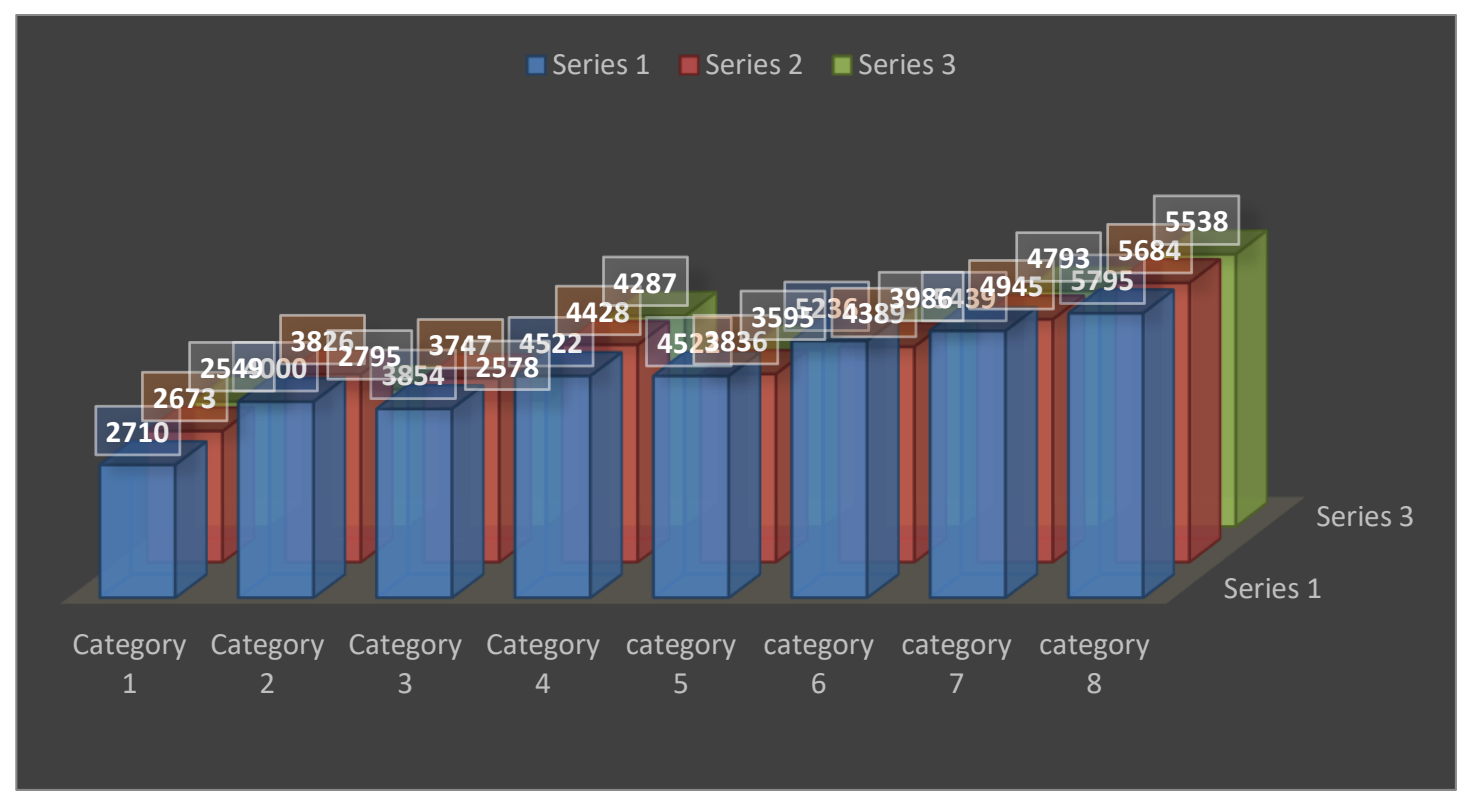

Figure 1. Upstream Intersection Maximum Throughput Variation with Incident Location and Duration $(\mathrm{v} / \mathrm{Ic}=1.13)$ at the Incident Location.

Nexo Revista Científica / Vol. 33, No. 01, pp. 200-212 / Junio 2020 


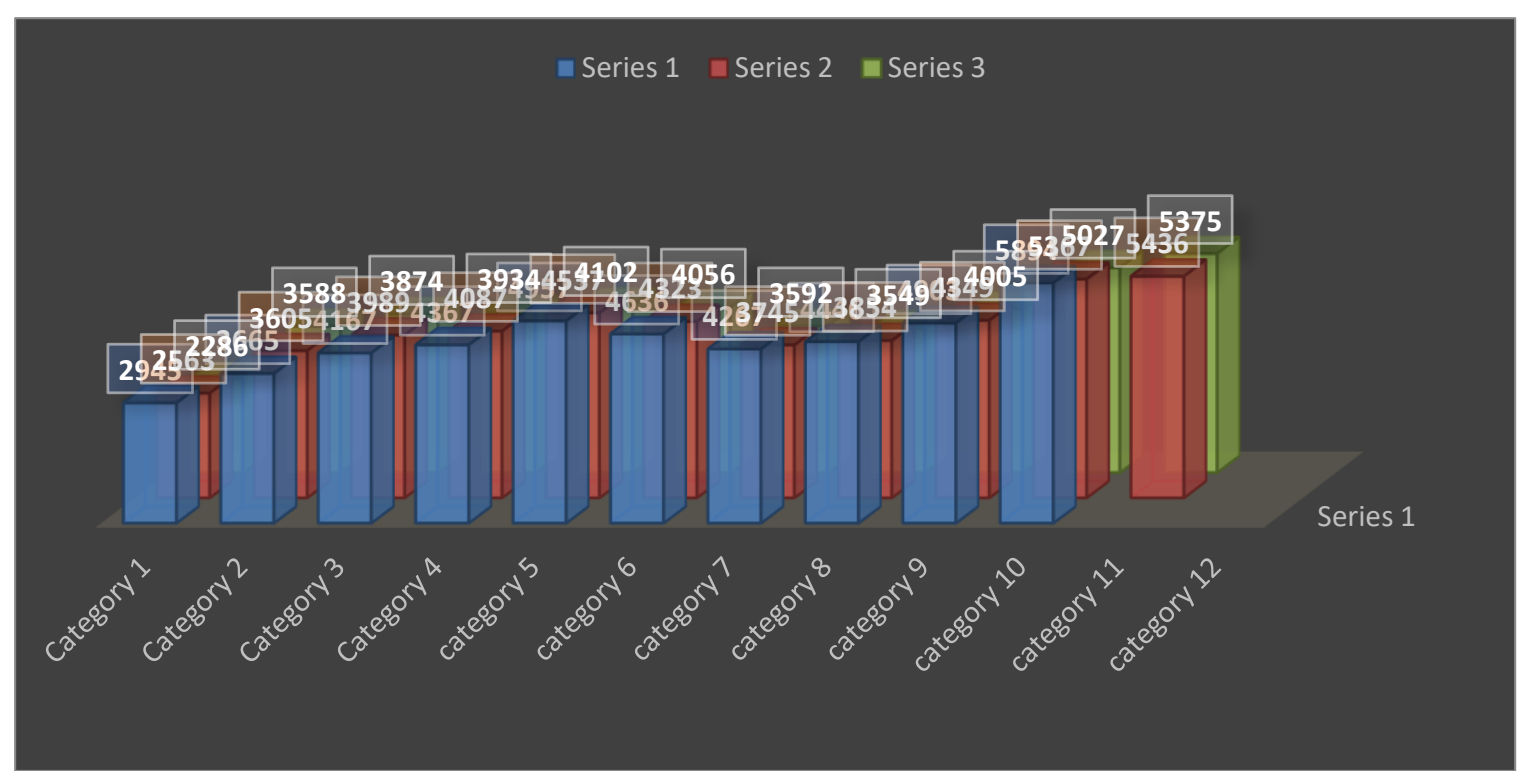

Figure 2. Upstream Intersection Maximum Throughput Variation with Incident Location and Duration $(\mathrm{v} / \mathrm{Ic}=1.3)$ at the Incident Location

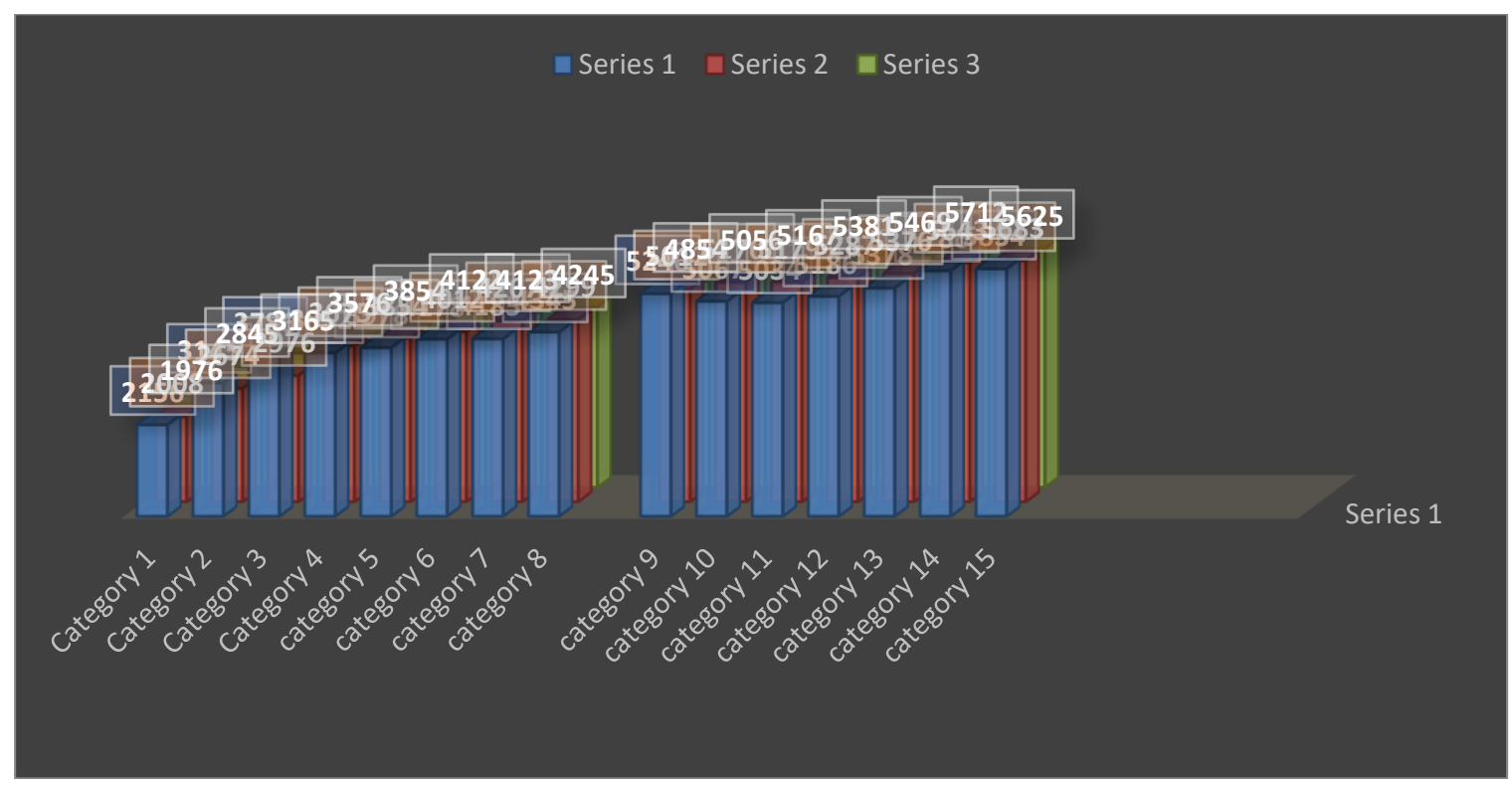

Figure 3. Upstream Intersection Maximum Throughput Variation with Incident Location and Duration $(\mathrm{v} / \mathrm{Ic}=1.5)$ at the Incident Location.

As seen in Figures 1 to 3, the throughput decreases with the increase in the v/Ic ratio at the incident location and the decrease in the distance between the upstream intersection and the incident location. As stated earlier, when an incident occurs at a location downstream of an upstream intersection, the throughput of the upstream links that feed the incident link can decrease if the queue from the incident spills back to the upstream links. For incidents that cause queueing due to demand exceeding the capacity at the incident location, when the signal phases serving the upstream feeding links are red, the downstream link queue starts decreasing due to the reduction in the arrivals at the back of the queue. This creates some queuing capacity that can accommodate flows from the upstream links in the green phase. 
During the first parts of the upstream link green phases, referred to as the "unconstrained green", the vehicles will be able to leave the stop lines of the feeding links at the saturation flow rates of these links until the queue due to the downstream incident spills back to the upstream signal again. The duration of the unconstrained green was calculated based on the following relationships:

$$
M T=S F \times U G / C+I C \times(T G-U G) / C
$$

$\boldsymbol{U} \boldsymbol{G}=$ upstream intersection unconstrained green time

$M T=$ intersection maximum throughput

$\boldsymbol{T} \boldsymbol{G}=$ upstream intersection green time

$C=$ cycle length

$\boldsymbol{I c}=$ capacity at the incident location, and

$\boldsymbol{S F}=$ saturation flow.

Table 3 presents the variation in the unconstrained green as a function of the demand to capacity ratio at the incident location, incident duration and the distance from the upstream intersection to the incident location. Table 3 shows the regression analysis models developed in this study to estimate the maximum throughput and the unconstrained green of the upstream intersection as a function of the independent variables. The $\mathrm{x}$ in the table is the incident distance from the upstream intersection in feet.

Table 3. Variation in Upstream Unconstrained Green in Terms of Incident location, Duration and Volume to Incident Capacity (v/Ic) Ratio

\begin{tabular}{|c|c|c|c|c|}
\hline $\begin{array}{l}\mathrm{v} / \mathrm{Ic} \\
\text { incident } \\
\text { location }\end{array}$ & $\begin{array}{l}\text { Incident } \\
\text { Location }\end{array}$ & $\begin{array}{l}\text { Unconstrained Green for } \\
15 \text { Minut Incident }\end{array}$ & $\begin{array}{l}\text { Unconstrained Green for } \\
35 \text { Minut Incident }\end{array}$ & $\begin{array}{l}\text { Unconstrained Green for } \\
45 \text { MinuteIncident }\end{array}$ \\
\hline \multirow{8}{*}{1.13} & 55 & 27.02 & 22.51 & 18.33 \\
\hline & 110 & 32.14 & 36.33 & 25.12 \\
\hline & 165 & 46.35 & 46.44 & 31.12 \\
\hline & 220 & 59.23 & 55.13 & 47.44 \\
\hline & 275 & 65.39 & 59.43 & 52.27 \\
\hline & 330 & 67.43 & 60.12 & 53.56 \\
\hline & 385 & 72.22 & 62.13 & 54.32 \\
\hline & 440 & 80.00 & 80.00 & 80.00 \\
\hline \multirow{19}{*}{1.30} & 55 & 25.12 & 24.15 & 22.54 \\
\hline & 110 & 42.14 & 36.35 & 32.56 \\
\hline & 165 & 48.43 & 39.12 & 34.34 \\
\hline & 220 & 54.12 & 43.12 & 38.32 \\
\hline & 275 & 47.31 & 44.14 & 41.32 \\
\hline & 330 & 49.39 & 29.18 & 27.14 \\
\hline & 385 & 64.45 & 31.48 & 28.16 \\
\hline & 440 & 75.12 & 44.29 & 39.52 \\
\hline & 495 & 80.00 & 70.38 & 64.34 \\
\hline & 550 & 80.00 & 71.46 & 65.39 \\
\hline & 605 & 80.00 & 80.00 & 78.12 \\
\hline & 660 & 80.00 & 80.00 & 80.00 \\
\hline & 55 & 17.38 & 15.36 & 12.43 \\
\hline & 110 & 36.74 & 32.47 & 28.93 \\
\hline & 165 & 38.90 & 32.01 & 27.63 \\
\hline & 220 & 42.77 & 34.11 & 29.07 \\
\hline & 275 & 47.07 & 35.78 & 30.22 \\
\hline & 330 & 46.64 & 32.90 & 26.70 \\
\hline & 385 & 51.81 & 35.32 & 28.35 \\
\hline
\end{tabular}

Nexo Revista Científica / Vol. 33, No. 01, pp. 200-212 / Junio 2020 
Hooman Rahimi et al.

\begin{tabular}{|l|l|l|l|l|}
\hline 1.50 & 66.32 & 49.55 & 41.69 \\
\cline { 2 - 5 } & 440 & 76.77 & 50.46 & 50.59 \\
\hline 550 & 70.31 & 54.88 & 57.90 \\
\hline 605 & 71.60 & 55.06 & 36.31 \\
\hline 660 & 74.62 & 58.75 & 36.67 \\
\hline 715 & 78.00 & 65.71 & 42.84 \\
\hline 770 & 80.00 & 71.34 & 44.06 \\
\hline & 835 & 80.00 & 80.00 & 64.86 \\
\cline { 2 - 5 } & 890 & 80.00 & 80.00 & 80.00 \\
\hline
\end{tabular}

Table 4. Regression Models to Estimate Upstream Intersection Maximum Throughput and Unconstrained Green Regression Models

\begin{tabular}{|l|l|l|l|l|l|}
\hline $\begin{array}{l}\text { Incident } \\
\text { Duration }\end{array}$ & $\begin{array}{l}\text { v/Ic at } \\
\text { Incident } \\
\text { Location }\end{array}$ & $\begin{array}{l}\text { Intersection Movement } \\
\text { Maximum Throughput }\end{array}$ & $\mathrm{R} 2$ & Unconstrained Green & $\mathrm{R} 2$ \\
\hline \multirow{3}{*}{15 minutes } & 1.13 & $\mathrm{MT}=0.4858 \mathrm{x}+1243.6$ & 0.84 & $\mathrm{UG}=0.0439 \mathrm{x}+16.785$ & 0.9 \\
\cline { 2 - 6 } & 1.3 & $\mathrm{MT}=0.3317 \mathrm{x}+1256.7$ & 0.83 & $\mathrm{UG}=0.0315 \mathrm{x}+18.136$ & 0.85 \\
\hline \multirow{3}{*}{35 minetes } & 1.5 & $\mathrm{MT}=0.3534 \mathrm{x}+994.31$ & 0.85 & $\mathrm{UG}=0.0271 \mathrm{x}+19.117$ & 0.86 \\
\cline { 2 - 6 } & 1.13 & $\mathrm{MT}=0.4628 \mathrm{x}+13513.7$ & 0.81 & $\mathrm{UG}=0.0423 \mathrm{x}+16.696$ & 0.84 \\
\cline { 2 - 6 } & 1.3 & $\mathrm{MT}=0.3342 \mathrm{x}+1048$ & 0.83 & $\mathrm{UG}=0.0315 \mathrm{x}+15.183$ & 0.88 \\
\hline \multirow{3}{*}{45 minetes } & 1.5 & $\mathrm{MT}=0.2461 \mathrm{x}+828.35$ & 0.88 & $\mathrm{UG}=0.0253 \mathrm{x}+18.347$ & 0.86 \\
\cline { 2 - 6 } & 1.3 & $\mathrm{MT}=0.3632 \mathrm{x}+1153.4$ & 0.85 & $\mathrm{UG}=0.041 \mathrm{x}+8.8462$ & 0.89 \\
\cline { 2 - 6 } & 1.5 & $\mathrm{MT}=0.4256 \mathrm{x}+985.88$ & 0.89 & $\mathrm{UG}=0.0366 \mathrm{x}+11.35$ & 0.86 \\
\hline
\end{tabular}

\subsection{Modeling Incidents in Mesoscopic Simulation}

This approach was tested by running DTAlite with a small hypothetical network that has five nodes and four links. The first upstream link was designed to accommodate the expected queue of the arriving vehicles to the network, in case of spillback from the incident. The third link was considered as the link, on which an incident occurs at the midblock. The second link was the incident upstream link. One lane blockage incident with a 35-minute duration was modeled $600 \mathrm{ft}$. downstream from the upstream signal and $800 \mathrm{ft}$. away from the downstream signal. The incident started in the 990-minute time step of the simulation and was removed in the 1,025-minute time step. Five scenarios were developed to analyse the performance of the incident modeling in different ways in the DTAlite. incident. The third link was considered as the link, on which an incident occurs at the midblock. The second link was the incident upstream link. One lane blockage incident with a 35-minute duration was modeled $270 \mathrm{~m}$. downstream from the upstream signal and $800 \mathrm{ft}$. away from the downstream signal. The incident started in the 990-minute time step of the simulation and was removed in the 1,025-minute time step. Five scenarios were developed to analyse the performance of the incident modeling in different ways in the DTA lite .downstream $\mathrm{g} / \mathrm{C}$ ratio is 0.55 . The upstream signal $\mathrm{g} / \mathrm{C}$ ratio is also 0.60 , so that, the upstream node maximum flow is 2880 (veh/hr) for three lanes. The $\mathrm{V} / \mathrm{Ic}$ ratio at the incident location is equal to 1.40 . By using the regression model in Table 3 the upstream signal maximum saturation flow was calculated $(950 \mathrm{veh} / \mathrm{hr} / \mathrm{ln}$ or $2850 \mathrm{veh} / \mathrm{hr})$. Thus, the upstream signalized intersection capacity during the incident can be calculated by multiplying the upstream signal maximum throughput $(2850 \mathrm{veh} / \mathrm{hr})$ by its $\mathrm{g} / \mathrm{C}$ ratio $(0.6)$, which is equal to $1710 \mathrm{(veh/hr})$ or $(427$ $\mathrm{veh} / 15 \mathrm{~min})$.

As seen in the Table 5, the upstream signal capacity is about 690 (veh/15 minutes) without the incident. The second scenario shows that the upstream signal capacity starts to drop once the queue from the incident capacity location reaches the upstream signal according to the mesoscopic simulation modeling associated with the DTA tool. The results show that the queue reaches the upstream node 15 minutes after the incident

Nexo Revista Científica / Vol. 33, No. 01, pp. 200-212 / Junio 2020 
occurred because the utilized mesoscopic models the incident at the stop line. Also, the results show that the percentage drop in the incident capacity is the same at the incident location and upstream intersection location once the shockwave reaches the upstream intersection, which does not account for the inefficiency at the upstream intersection location described earlier. In the third scenario, the incident location was modeled with a dummy link and without the downstream signal queue spillback effects on its downstream incident. As can be seen, although the drop in capacity occurred earlier, the same drop in capacity result in Scenario 3 as in Scenario 2. In the fourth scenario, the drop in the incident capacity was modeled based on dropping the capacity on the dummy link and accounting from as seen in the Table 5, the upstream signal capacity is about 690 (veh/15 minutes) without the incident. The second scenario shows that the upstream signal capacity starts to drop once the queue from the incident capacity location reaches the upstream signal according to the mesoscopic simulation modeling associated with the DTA tool. The results show that the queue reaches the upstream node 15 minutes after the incident occurred because the utilized mesoscopic models the incident at the stop line. Also, the results show that the percentage drop in the incident capacity is the same at the incident location and upstream intersection location once the shockwave reaches the upstream intersection, which does not account for the inefficiency at the upstream intersection location described earlier. In the third scenario, the incident location was modeled with a dummy link and without the downstream signal queue spillback effects on its downstream incident. As can be seen, although the drop in capacity occurred earlier, the same drop in capacity result in Scenario 3 as in Scenario 2. In the fourth scenario, the drop in the incident capacity was modeled based on dropping the capacity on the dummy link and accounting from downstream signal queue spillback. The downstream signal's effects on capacity is indicated by dropping the incident throughput from 500 (veh/15 min) to (474 veh/15 $\mathrm{min}$ ). However, this drop still did not account for the inefficiency in upstream signal operations. The last scenario was designed based on the proposed method and the results show that the combination of the derived regression model and the DTA tool modeling can account for this effect by dropping the capacity further to 427 (veh/15 min).

Table 5. Upstream Signal Maximum Throughput for the Test Scenarios

\begin{tabular}{|l|l|l|l|l|l|l|}
\hline $\begin{array}{l}\text { Time } \\
\text { Stamp } \\
\text { min }\end{array}$ & $\begin{array}{l}\text { Scenario 1 } \\
\text { Upstream } \\
\text { Node } \\
\text { Throughput } \\
\text { (veh/15min) }\end{array}$ & $\begin{array}{l}\text { Scenario 2 } \\
\text { Upstream } \\
\text { Node } \\
\text { Throughput } \\
\text { (veh/15min }\end{array}$ & $\begin{array}{l}\text { Scenario 3 } \\
\text { Upstream } \\
\text { Node } \\
\text { Throughput } \\
\text { (veh/15 min }\end{array}$ & $\begin{array}{l}\text { Scenario 4 } \\
\text { Upstream } \\
\text { Node } \\
\text { Throughput } \\
\text { (veh/15min) }\end{array}$ & $\begin{array}{l}\text { Scenario 4 } \\
\text { Incident } \\
\text { Location } \\
\text { Throughput } \\
\text { (veh/15min) }\end{array}$ & $\begin{array}{l}\text { Scenario 5 } \\
\text { Upstream } \\
\text { Node } \\
\text { (veh/15min) }\end{array}$ \\
\hline 970 & 158 & 158 & 158 & 158 & 158 & 158 \\
\hline 985 & 688 & 688 & 688 & 688 & 688 & 688 \\
\hline 1000 & 689 & 647 & 500 & 474 & 474 & 427 \\
\hline 1015 & 688 & 500 & 500 & 474 & 474 & 427 \\
\hline 1030 & 690 & 500 & 768 & 768 & 746 & 760 \\
\hline 1045 & 689 & 689 & 877 & 878 & 877 & 878 \\
\hline 1060 & 688 & 688 & 878 & 877 & 878 & 877 \\
\hline 1075 & 689 & 689 & 695 & 696 & 688 & 696 \\
\hline 1090 & 687 & 687 & 675 & 675 & 675 & 675 \\
\hline 1105 & 688 & 675 & 675 & 676 & 676 & 676 \\
\hline 1120 & 689 & 689 & 642 & 674 & 675 & 674 \\
\hline
\end{tabular}

\subsection{Special Signal Timing Plan}

The implemented special signal timing plan was to divide the upstream signal incident movement green time (i.e., 61 seconds for a 45 -minute incident) into two parts to reduce the spillback effect that block the green time at the end of a long green. The first green phase of the upstream main street movement was set to the estimated unconstrained green estimated using the models presented. After the first green time, the upstream signal main street movement green was terminated and the greens of the cross street movements were turned on. Once the cross streets' movement green were terminated, a green time was assigned to the 
EB and WB green movements again as shown in the Figure. 4 (EB1 \& WB1). This new signal plan was set to start when the incident queue reaches the upstream signal and remained in effect until the incident queue was determined to have no impact on the upstream signal.

Normal Condition Signal Control Plan

\begin{tabular}{|c|c|c|c|c|}
\hline $\begin{array}{c}\varnothing 128 \mathrm{sec} \\
\text { EBL }\end{array}$ & $\begin{array}{c}\text { O2 } 60 \mathrm{sec} \\
\text { WB }\end{array}$ & $\begin{array}{c}0326 \mathrm{sec} \\
\text { SBL }\end{array}$ & $\begin{array}{c}6447 \mathrm{sec} \\
\text { NB }\end{array}$ & \\
\hline $\begin{array}{c}0527 \mathrm{sec} \\
\text { WBL }\end{array}$ & $\begin{array}{c}9661 \mathrm{sec} \\
\text { EB }\end{array}$ & $\begin{array}{c}0741 \mathrm{sec} \\
\mathrm{NBL}\end{array}$ & & $\begin{array}{c}0832 \mathrm{sec} \\
\mathrm{SB}\end{array}$ \\
\hline
\end{tabular}

Special Signal Timing Plan for the Incident

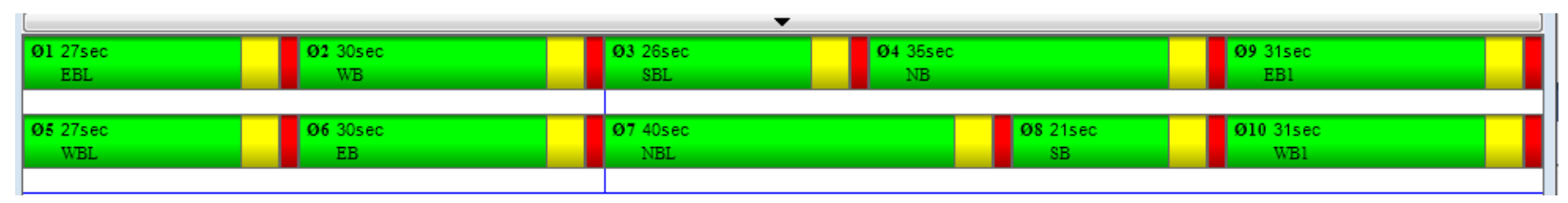

Figure 4. Signal Control Plan for Normal Day vs. Special Signal Control Plan

\section{CONCLUSIONES}

This study demonstrates the need for and utilization of a multi-resolution and multiscenario modeling approach to support the evaluation and design of ATM strategies. Most ATM strategies are effective in relieving congestion during non-typical days and patterns with high demands, incidents with different severity levels, and adverse weather conditions. This research highlights the importance of modeling different traffic patterns when assessing the benefits of dynamic signal control that is responsive to traffic and incident conditions. The days that correspond to different percentiles of traffic, such as the 50th, 75th, and 95th percentiles were determined and modeled using a mesoscopics imulation- based DTA. The origindestination demands for the three levels were determined utilizing an ODME process based on a seed matrix and traffic counts for the three days. It was determined that current methods of calibrating the demands utilizing ODME modules based on segment counts is not adequate enough to produce accurate estimates of the turning movement counts and that the inclusion of turning movement counts as an input to the ODME is necessary.

The study then demonstrated the use of the DTA model with this setup to produce turning movement volumes for different demand levels to input into signal optimization and microscopic simulation modeling tools to assess the impact of dynamic signal control. The Highway Capacity Software (HCS) was used to optimize the signal timing for different traffic patterns, and the resulting signal timings were evaluated using microscopic simulation to evaluate the traffic response signal control performance. The results indicate that the delay resulting from the implementation the traffic response signal control strategies can be reduced significantly and that this method can be used as part of planning for operations to evaluate and design strategies.

This study also investigated the method used to assess incident responsive dynamic signal control. An important aspect of the assessment is to determine the capacity impacts of the interaction between the drop in capacity below demands at the midblock urban street segment location and the upstream and downstream signalized intersection operations. A model was developed to estimate the drop in capacity at the incident location as a function of the number of blocked lanes, distance from downstream intersection, and $\mathrm{g} / \mathrm{C}$ ratio of the downstream signal. A second model was developed to estimate the reduction in the upstream

Nexo Revista Científica / Vol. 33, No. 01, pp. 200-212 / Junio 2020 


\section{Hooman Rahimi et al.}

intersection capacity due to the drop in capacity at the midblock incident location as estimated by the first model. The second model estimates the drop in capacity of the upstream links feeding the incident locations as a function of incident duration time, v/c ratio at the incident location, and distance from an upstream signalized intersection. The developed regression models show significant relationships between the drops in incident capacity and the drops in upstream saturation flow as dependent and independent variables in the model. The focus of this study was on a three-lane arterial facility because three lane facilities are the most common type of principal urban street facilities. However, the second model that estimates upstream intersection flow rates is applicable to facilities with a different number of lanes. The developed capacity reduction models were used to estimate delay due to an urban street incident. The delay was calculated as a combination of the delay due to queuing on the incident link and the increase in upstream intersection control delays due the reduction in maximum throughputs resulting from queue spillback to the upstream intersection. A comparison with microscopic simulation modeling results showed that the delay estimated using the combination of the increase in control delay based on the reduction in capacity estimated by the developed models and deterministic queuing at the incident location produced better results than using the deterministic queuing procedure by itself for estimating delays.

The developed method to estimate urban street incident impacts was then implemented as part of the multiresolution modeling to refine the DTA modeling and as an input to the highway capacity manual-based modeling of incident and incident responsive management impacts. To supplement the DTA modeling for this purpose, additional regression models were developed to estimate diversion due to urban street incidents. These regression models were combined with the DTA model to estimate the volumes at the incident location and alternative routes. The produced volumes during theincident were then used as inputs to microscopic simulation for more detailed analysis and to demonstrate the benefits of special signal plans during incident conditions.

\section{REFERENCIAS}

Aghdashi, B., Khazraeian, S., Trask, J., Hadi, M., \& Rouphail, N. (2017). Incorporating Adaptive (Traffic Responsive) Ramp Metering in the Highway Capacity Manual Context. Paper presented at the Proceedings of the 96th Annual Meeting of the Transportation Research Board.

Al-Nuaimi, H., Ayers, R., \& Somasundaraswaran, K. (2013). Traffic flow modelling for an urban arterial road in Brisbane City. Paper presented at the Proceedings of the 14th Road Engineering Association of Asia and Australasia Conference (REAAA 2013).

Avetisyan, H. G., Miller-Hooks, E., Melanta, S., \& Qi, B. (2014). Effects of vehicle technologies, traffic volume changes, incidents and work zones on greenhouse gas emissions production. Transportation research part D: transport and environment, 26, 10-19.

Bhide, V. (2005). Strategies for incident management in an urban street network.

Hadi, M., Sinha, P., \& Wang, A. (2007). Modeling reductions in freeway capacity due to incidents in microscopic simulation models. Transportation research record, 1999(1), 62-68.

Hadi, M., Xiao, Y., Wang, T., Qom, S. F., Azizi, L., Iqbal, M. S., . . Massahi, A. (2016). Framework for multi-resolution analyses of advanced traffic management strategies.

Hong, C., Yue-sheng, Y., \& Bin, Z. (2013). A Capacity Assessment Method on Urban Expressway after Traffic Incident. Procedia-Social and Behavioral Sciences, 96, 1921-1928.

Nexo Revista Científica / Vol. 33, No. 01, pp. 200-212 / Junio 2020 
Jin, X., Hossan, S., Asgari, H., \& Shams, K. (2018). Incorporating attitudinal aspects in roadway pricing analysis. Transport Policy, 62, 38-47.

Khazraeian, S., Hadi, M., \& Xiao, Y. (2017). Assessment of the Benefits of Queue Warning in a Connected Vehicle Environment based on Surrogate Safety Measures. Paper presented at the Proceedings of the 96th Annual Meeting of the Transportation Research Board, Washington.

Khazraeian, S., Xiao, Y., Hadi, M., \& Aghdashi, S. (2015). Application of the Upcoming HCM Managed Lane Procedure to Pylon-Separated Managed Lane Analyses. Paper presented at the Proceedings of the 94th Annual Meeting of the Transportation Research Board, Washington, DC, January 2015.

Kim, S.-J., Kim, W., \& Rilett, L. R. (2005). Calibration of microsimulation models using nonparametric statistical techniques. Transportation Research Record, 1935(1), 111-119.

Shams, K., Jin, X., Fitzgerald, R., Asgari, H., \& Hossan, M. (2017). Value of Reliability for Road Freight Transportation: Evidence from a Stated Preference Survey in Florida. Transportation Research Record, 2610(1), 35-43.

Zegeer, J., Bonneson, J. A., Dowling, R. G., Ryus, P., Vandehey, M., Kittelson, W., . . Aghdashi, B. (2014). Incorporating travel time reliability into the Highway Capacity Manual: National Research Council (US). Transportation Research Board.

Zhou, X., \& Taylor, J. (2014). DTALite: A queue-based mesoscopic traffic simulator for fast model evaluation and calibration. Cogent Engineering, 1(1), 961345. 